\title{
The Excellent Mechanical Properties of Cork: A Novel Approach through the Analysis of Contact Stress
}

\author{
Antonio Díaz-Parralejo, ${ }^{1}$ Eduardo M. Cuerda-Correa, ${ }^{2}$ Antonio Macías-García, ${ }^{1}$ \\ José Sánchez-González, ${ }^{1}$ and M. Ángeles Díaz-Díez ${ }^{1}$ \\ ${ }^{1}$ Department of Mechanical, Energetic and Materials Engineering, School of Industrial Engineering, University of Extremadura, \\ Avenida de Elvas, s/n, 06071 Badajoz, Spain \\ ${ }^{2}$ Department of Organic and Inorganic Chemistry, Faculty of Sciences, University of Extremadura, Avenida de Elvas, \\ $s / n, 06071$ Badajoz, Spain
}

Correspondence should be addressed to Eduardo M. Cuerda-Correa; emcc@unex.es

Received 18 February 2014; Accepted 30 March 2014; Published 7 May 2014

Academic Editors: P. Mandracci, Y. Sun, and R. A. Varin

Copyright (C) 2014 Antonio Díaz-Parralejo et al. This is an open access article distributed under the Creative Commons Attribution License, which permits unrestricted use, distribution, and reproduction in any medium, provided the original work is properly cited.

In many technological applications of cork, this biomaterial is under strongly localized contact stresses, which largely differ from the homogeneous distribution of stresses of the typical uniaxial compression tests. Indentation tests constitute an excellent form of determining the behavior of the materials under localized stresses. In the present study, the applicability of Hertzian and Brinell indentation tests to the evaluation of the mechanical properties of cork is tested. One of the main conclusions of the study is that the elastic anisotropy of the material is related to the anisotropic structure of the different sections cut from a cork sample, a clear difference between the back tangential section and the other sections being observed.

\section{Introduction}

Cellular solids are materials possessing cellular microstructures, which are seen in natural materials such as wood, cork, sponge, cancellous bone, and coral [1]. This kind of materials usually exhibit excellent energy absorption characteristics under compression. Thus, the study of the deformation behavior of cellular solids under compression has received a great deal of attention $[2,3]$.

Cork is a widely used material due to its excellent mechanical properties, low density, impermeability, thermal and acoustic insulation, and so forth. Examples of its use are as the stopper in bottles of quality wine, floorings, and wall coverings, and so forth. Despite its qualities for such a diversity of applications, there has been a certain unjustifiable lethargy in scientific attention to this material. There have however been some recent studies published on the structure and mechanical properties of cellular solids in general $[4,5]$, and on the mechanical properties of cork in particular [6-8], which have helped to better understand the unique properties of this material. In this connection, cork and its derivatives have been used as new biosources of chemicals [9] and as the precursor for the preparation of cation exchangers [10] and, more recently, for the preparation of activated carbons for the removal of pollutants from solution [11].

In many technological applications, cork is subjected to strong contact stresses localized in small zones of the material, not to the homogeneous distribution of stresses that are involved in uniaxial compressive strength tests. The mechanical behavior of other materials such as foams of different types has been tested [2]. Nevertheless, there have been no studies on the mechanical response of the material under such conditions. In this regard, indentation tests are an excellent form of assessing the damage and behavior of materials under localized stresses [12]. Among the different methods (Hertzian, Vickers, Brinell, etc.), the Hertzian indentation test is particularly interesting because it allows one to control the contact pressure on the material 

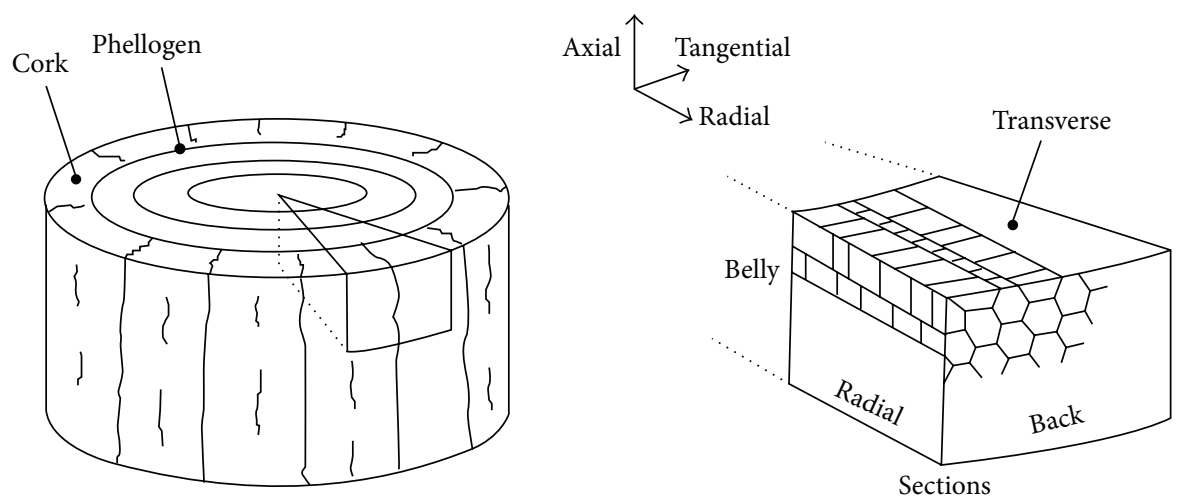

FIGURE 1: Diagram showing the different sections and directions of a piece of cork relative to its position on the tree. Also indicated above is the morphology of the cells of each section.

from very low values (elastic and/or viscoelastic response) up to values high enough to generate irreversible damage in the material.

The Hertzian test involves the application of a load, $P$, onto the surface of the material using spherical indenters (usually made of a hard material such as tungsten carbide, WC). This test is traditionally used to investigate the plasticity of metallic materials and, more recently, to study the fracture of ceramics [13-15]. In the present study, we will also demonstrate its utility in investigating the mechanical properties of cork.

Cork is a natural product of the cork oak (Quercus suber L.). Cork cells are generated by the activity of phellogen [16]. They are stacked in columns with axes parallel to the radial direction of the tree (Figure 1). The "radial" and "transverse" sections are arranged in columns parallel to the radial direction. The "tangential" sections are arranged perpendicular to the radial direction of the tree and have a honeycomb-like morphology. The size of the cells and the resulting thickness of each cork layer vary according to the conditions of the season in which they were formed [17]. The ranges of these dimensions are as follows: height $30-40 \mu \mathrm{m}$, edges of the bases $13-15 \mu \mathrm{m}$, cell wall thickness $1-2 \mu \mathrm{m}$, and layer thickness $200-3000 \mu \mathrm{m}$.

\section{Materials and Experimental Procedure}

2.1. Preparation of Samples. Samples of cork were supplied by the Institute for the Promotion of Cork, Wood, and Coal (ICMC, Spain). An automatic cutoff machine (Struers Accutom-50) with a diamond wheel was used to cut regular parallelepiped specimens (see Figure 1). For the "back" tangential section, the zone of outer crust (about $5 \mathrm{~mm}$ thick) was first removed, and for the "belly" tangential section, the layer (about $2 \mathrm{~mm}$ thick) in contact with the inner bark of the tree trunk was removed.

2.2. Mechanical Tests. The tests were performed on a universal testing machine (Instron Model 1122), applying loads in the range from 0 to $300 \mathrm{~N}$ using spherical tungsten carbide (WC) indenters of radii 5.5 and $12.7 \mathrm{~mm}$. The speed of application of the load was $0.05 \mathrm{~mm} / \mathrm{min}$. After several trials (gold sputtering onto the sample, spraying with ink, etc.), it was decided that the best approach to defining the region of contact during indentation was to cover the WC ball with ink. The contact radius was measured under optical microscopy using a digital comparator clock coupled to the mobile turntable.

2.2.1. Hertzian Indentation Test. In Hertzian indentation test, the stress field scales with the contact pressure, $p_{0}$, also known as the indentation stress [13]:

$$
p_{0}=\frac{P}{\pi a^{2}},
$$

where $P$ is the indentation load and $a$ the radius of the circle of contact (Figure 2). In accordance with the principle of geometric similarity, the strain field scales with the ratio $a / r$, where $r$ is the radius of the sphere. This ratio is called the indentation strain. The experimental determination of $a$ for each indentation load and indenter radius, $r$, allows one to obtain the indentation stress-strain curve: $p_{0}(a / r)$, which is characteristic of each material and independent of the radius of the indenter. Figure 2 shows a generic stressstrain indentation curve. The linear part corresponds to the elastic contact domain. Beyond a certain threshold of stress, the response is no longer linear, indicating the onset of irreversible processes that generate some level of damage to the material [13]. Under elastic contact conditions, one has that

$$
p_{0}=\frac{3 E a}{4 \pi k r}
$$

where $E$ is material's Young's modulus and $k$ is the dimensionless constant

$$
k=\frac{9}{16}\left[\left(1-v^{2}\right)+\left(1-v^{\prime 2}\right)\right] \frac{E}{E^{\prime}},
$$

where $v, v^{\prime}, E$, and $E^{\prime}$ are the Poisson ratios and Young's moduli of the specimen and indenter, respectively. Thus, knowing the elastic constants of the indenter, one can 

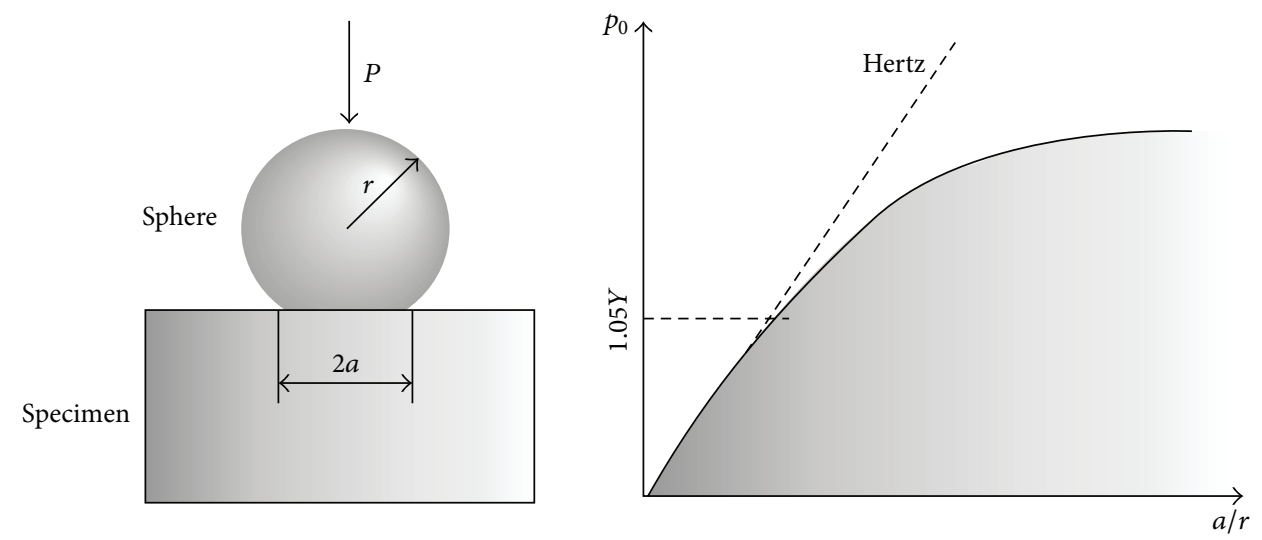

Figure 2: Diagram of a Hertzian indentation test (left) and typical indentation stress-strain curve (right). $Y$ is the yield stress of an uniaxial test.

estimate the value of $E$ from the linear segment of the experimental indentation stress-strain curve. According to the Tresca-Guest criterion, which is reasonably acceptable for ductile materials subjected to situations of high shear stresses, inelastic deformation begins at a point of the solid where the maximum tangential stress reaches the value

$$
\tau_{m}=\frac{Y}{2}
$$

with $Y$ being the yield stress.

In Hertzian elastic contact theory, the shear stress is maximum on the load axis at a depth of $0.5 a$, with this value being approximately

$$
\tau_{m}=0.47 p_{0} .
$$

Thus, from (4), one finally has

$$
p_{Y}=1.05 Y \text {. }
$$

2.2.2. Brinell Indentation Tests. In a Brinell test, hardened steel spheres are used to produce an imprint on the surface of the tested material. The diameter of the imprint is measured, and the hardness (HBN) of the material is calculated from the relationship between the applied load and the area of the imprint. The area can be substituted by the diameter of the imprint, with the final expression being

$$
\mathrm{HBN}=\frac{P}{(\pi / 2) D\left[D-\sqrt{\left(D^{2}-d^{2}\right)}\right]},
$$

where $P$ is the applied load, $D$ is the diameter of the ball, and $d$ is the diameter of the imprint. For the results from different materials to be comparable, the applied loads must be proportional to the square of the diameter of the ball used for the imprints, that is,

$$
P=K D^{2} .
$$

The coefficient $K$ depends on the type of material to test, being greater for hard materials and smaller for soft materials.

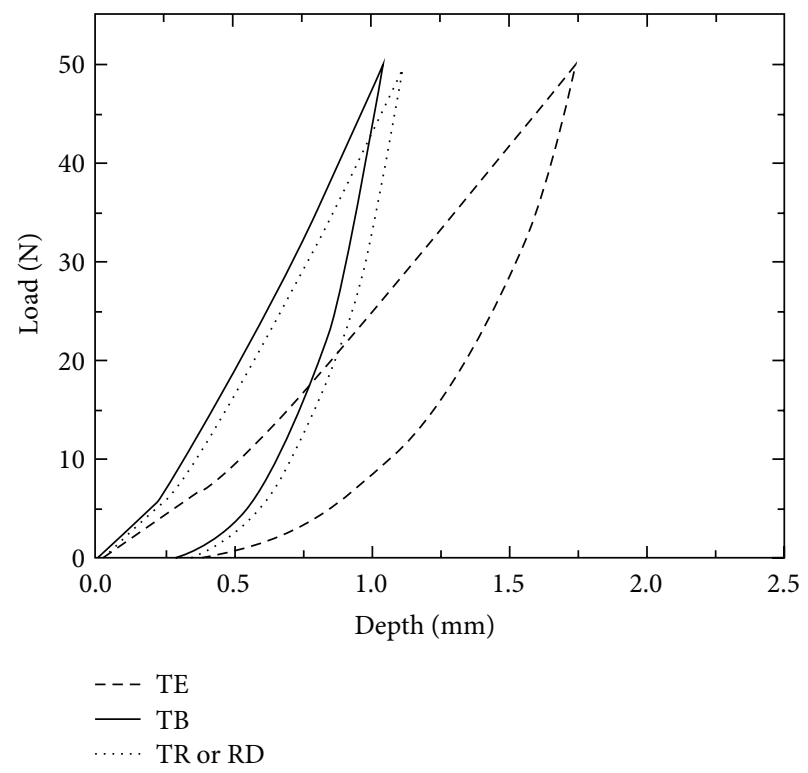

FIGURE 3: Load-unload curves corresponding to the different sections of a cork specimen.

A further constraint that must be satisfied to avoid bending in the specimen is that the diameter of the imprint must be within the range $D / 4<d<D / 2$, that is, approximately $d=$ $0.375 D$.

\section{Results and Discussion}

3.1. Load-Displacement Curves. Figure 3 shows the experimental load-displacement curves corresponding to different sections. These curves were obtained from each of the indentations carried out to determine the Hertzian indentation stress-strain curve. One observes that the tangential section corresponding to the "back" of the sample (TE) is weaker than that corresponding to the "belly" (TB). In addition, the TE section is weaker than the transverse (TR) and radial (RD) sections, although the differences depend on the depth 


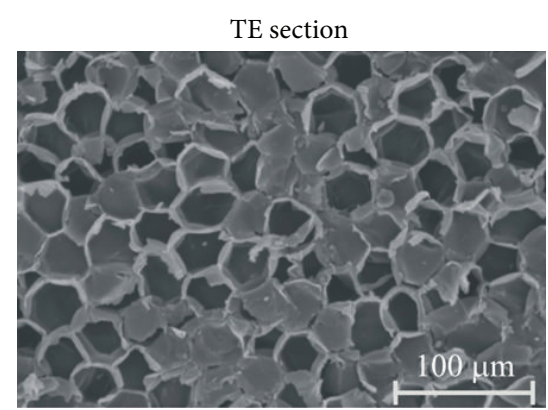

TR or RD section

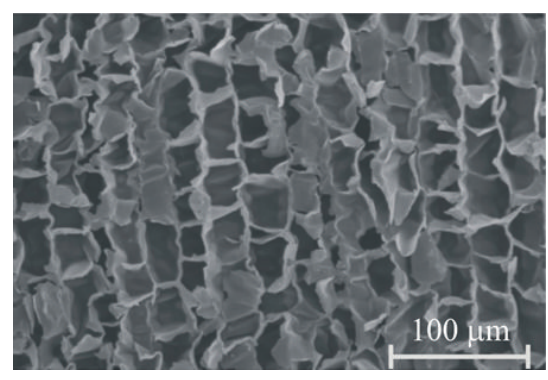

(a)

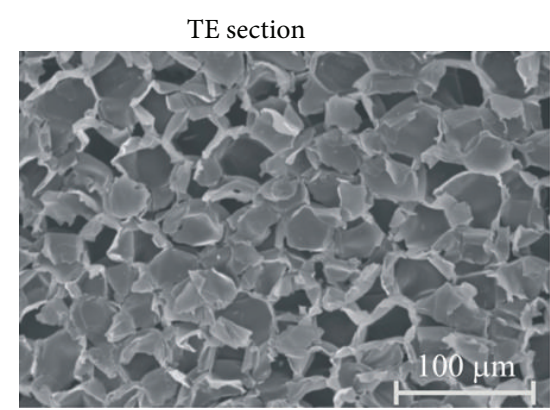

TR or RD section

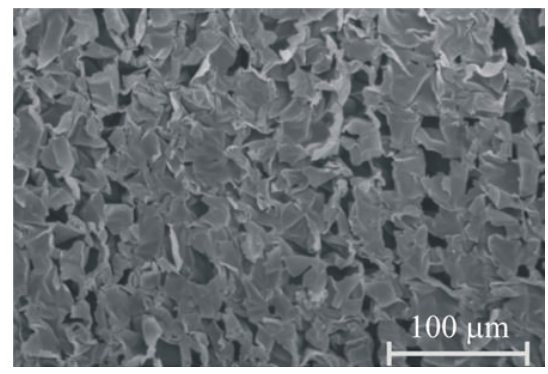

(b)

FIGURE 4: SEM micrographs of the TE and the TR or RD sections (a) before and (b) after applying a contact load of $100 \mathrm{~N}$.

at which the tests were performed with respect to the TE section.

In general, a large deformation of the specimen at relatively low loads is observed. In the unloading curve, one observes an initial slow recovery which increases as the load is released, although the energy stored by the sample is still relatively high at total unloading. Above a certain value (between 6 and $10 \mathrm{~N}$ ), the load curve deviates from a more or less linear behaviour, showing increasing resistance to deformation. This change is probably due to the progressive collapse of cells with increasing contact pressure.

The same effect can be seen in Figure 4 which shows the contact deformations of different sections of the same sample with a load of $100 \mathrm{~N}$. There is a notable difference between the deformation and damage in the back tangential section (TE) and the other sections. The TE section shows greater recovery and less damage after applying the contact stress, as is clearly observable in the figure in the cell walls. This fact is in accordance with other results previously reported in the literature [18].

3.2. Indentation Stress-Strain Curves. Figure 5 shows the experimental indentation stress-strain curves corresponding to the different sections of a given sample. The results show a first linear zone up to a certain value of $p_{0}$ that depends on the section being tested. While the results for the sections $\mathrm{TR}, \mathrm{RD}$, and $\mathrm{TB}$ are practically indistinguishable, the curve corresponding to the TE section is clearly unlike the rest, reflecting the relative weakness of this section. Young's moduli calculated from the linear zone of the curves are listed in Table 1. The means of these elastic constants for the samples tested are $7.2 \pm 0.5 \mathrm{MPa}$ for the TE section and $18 \pm 1.0 \mathrm{MPa}$ for the rest of the sections. This elastic anisotropy

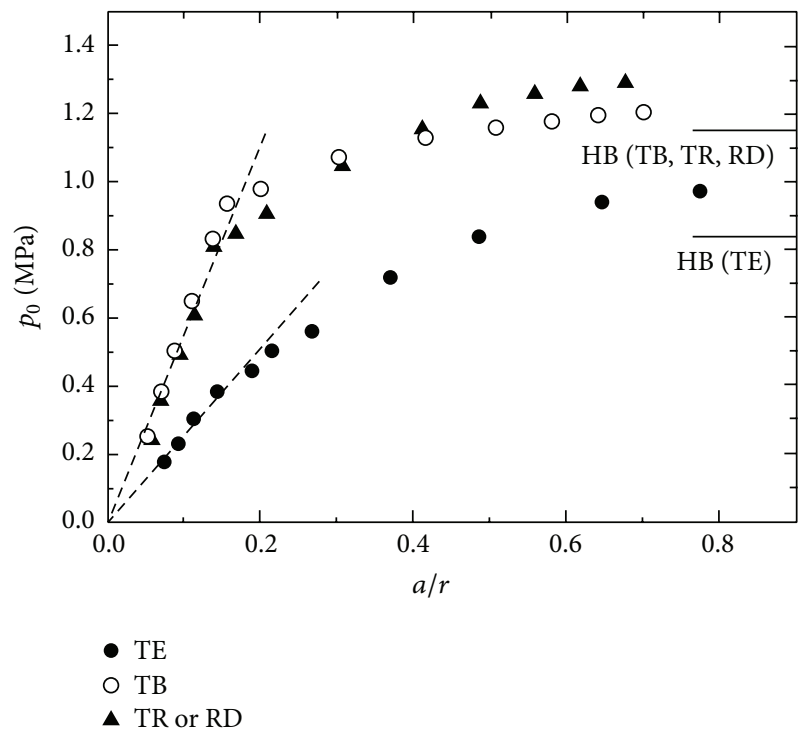

FIGURE 5: Indentation stress-strain curves for the TE, TB, TR, or RD sections of a cork sample.

is a reflection of the anisotropic structure of cork itself. The TE section is weaker than TB because it is the outer tangential layer. Indeed, the innermost cells are formed after the more external cells, and as they grow therefore have to push the latter outwards. This results in relatively greater density of the cell walls in the TB section, and consequently a greater resistance to elastic deformation. This kind of behavior has been reported by other researchers $[19,20]$ that have studied the hyperelastic or viscoelastic behavior of cork and its derivatives. 
TABLE 1: Young's modulus $(E)$, yield stress $(Y)$, and Brinell hardness $(\mathrm{HBN})$ of the different sections of some cork samples.

\begin{tabular}{|c|c|c|c|c|c|c|}
\hline \multirow{2}{*}{ Sample } & \multicolumn{2}{|c|}{$E(\mathrm{MPa})$} & \multicolumn{2}{|c|}{$Y(\mathrm{MPa})$} & \multicolumn{2}{|c|}{ HBN (MPa) } \\
\hline & $\mathrm{TE}$ & $\mathrm{TB}, \mathrm{RD}$, and $\mathrm{TR}$ & TE & $\mathrm{TB}, \mathrm{RD}$, and $\mathrm{TR}$ & TE & $\mathrm{TB}, \mathrm{RD}$, and $\mathrm{TR}$ \\
\hline M1 & $7.0 \pm 0.5$ & $18.0 \pm 1.0$ & $0.50 \pm 0.05$ & $0.80 \pm 0.05$ & $0.80 \pm 0.05$ & $1.10 \pm 0.05$ \\
\hline M2 & $6.6 \pm 0.5$ & $17.8 \pm 1.0$ & $0.50 \pm 0.05$ & $0.78 \pm 0.05$ & $0.85 \pm 0.05$ & $1.20 \pm 0.05$ \\
\hline M3 & $8.2 \pm 0.5$ & $18.4 \pm 1.0$ & $0.52 \pm 0.05$ & $0.80 \pm 0.05$ & $0.80 \pm 0.05$ & $1.10 \pm 0.05$ \\
\hline M4 & $7.2 \pm 0.5$ & $18.0 \pm 1.0$ & $0.52 \pm 0.05$ & $0.80 \pm 0.05$ & $0.82 \pm 0.05$ & $1.20 \pm 0.05$ \\
\hline
\end{tabular}

3.3. Determination of the Yield Stress. The yield stress of the cork samples was obtained from the critical indentation stress for the onset of plastic deformation (6). The estimation of $p_{Y}$ from the point at which the indentation stress-strain curve deviates from linearity involves a noticeable difficulty. We therefore used a method which consists of determining $p_{Y}$ from the load, $P_{Y}$, corresponding to the first detectable residual impression in the test surface and the corresponding contact radius, $a$. To this end, a series of tests were conducted using an indenter of known radius $(r=5.55 \mathrm{~mm})$ and increasing loads, and then observing the specimen under an optical microscope to identify the smallest load at which a residual impression was observable. The values calculated for the yield stress in the various sections and samples are also given in Table 1 . The mean values are $0.5 \pm 0.05 \mathrm{MPa}$ for the TE sections and $0.8 \pm 0.05 \mathrm{MPa}$ for the rest $(\mathrm{TB}, \mathrm{RD}$, and TR). It should be mentioned that the value obtained by this method is actually a slightly high estimate of the yield stress, as the measured value of $P_{Y}$ may be in excess. Indeed, for loads somewhat smaller than $P_{Y}$, plastic deformation may occur but be located in such a small region that it does not give rise to a residual impression detectable under optical microscopy.

3.4. Determination of the Brinell Hardness Index. To determine the Brinell hardness index, one must first fix the testing constant, $K$, to use depending on the nature of the material under test. As reference, some of the usual constants used to evaluate hardness in industrial materials are $K=30$ for steels; $K=10$ for $\mathrm{Cu}$, brasses, and bronzes; $K=5$ for light alloys; $K=2.5$ for $\mathrm{Sn}$ and $\mathrm{Pb}$, and so forth. Values of 1.25 and 0.5 are also used for very soft metals or alloys. In the case of a material such as cork, it is necessary to gradually decrease the value of the constant until the relationship between the applied force and the diameter of the sphere used produces an imprint, that is, within the limits established for the Brinell test, that is, $D / 4<d<D / 2$. In this way, we determined the value used to be $K=1.56 \cdot 10^{-2}$. The results using this constant are listed in Table 1. One observes that the Brinell hardness in the TE sections varies around $0.82 \pm 0.05 \mathrm{MPa}$ and around $1.15 \pm 0.05 \mathrm{MPa}$ in the other sections (TB, RD, and TR). These values are included in the plots of Figure 5. One sees that they are reasonably consistent with the Hertzian indentation tests. Indeed, Hertzian indentation stress surpassed the Brinell hardness values of each section because there is no constraint in the Hertzian tests on the diameters of the imprints, which can even exceed the upper bound of the Brinell imprints, that is, $d>D / 2$.

\section{Conclusions}

In this study, Hertzian and Brinell indentation tests were used to evaluate the mechanical properties of cork. The main conclusions and implications to be drawn from the study are as follows.

(i) The methodological approach is well suited to the characterization of the elastic and plastic behaviour of soft materials of diverse nature (cellular materials).

(ii) The observed elastic anisotropy is closely related to the anisotropic structure of the different sections of cork. The "back" tangential section is weaker than the other sections of the material.

(iii) The specimens presented large deformations at relatively low stresses, consistent with the low value of the material's elastic modulus. The material's elastic zone was relatively small (low values of the yield stress), but well defined.

(iv) Finally, we wish to note that Hertzian and Brinell indentation testing would seem to be well suited not only to characterize mechanically such materials as cork, but also to evaluate the intrinsic quality of these materials.

\section{Conflict of Interests}

The authors declare that they have no affiliations with or involvement in any organization or entity with any financial interest (such as honoraria, educational grants, participation in speakers bureaus, membership, employment, consultancies, stock ownership, or other equity interests, and expert testimony or patent-licensing arrangements), or nonfinancial interest (such as personal or professional relationships, affiliations, knowledge, or beliefs) in the subject of matter or materials discussed in this paper. Consequently, the authors declare that there is no conflict of interests regarding the publication of this paper.

\section{Acknowledgments}

The authors thank Dr. A. Pajares and Dr. A. L. Ortiz for the fruitful discussion and the Institute for the Promotion of Cork, Wood, and Coal (ICMC), Junta de Extremadura (Spain), for supplying the cork samples. 


\section{References}

[1] Y. Takahashi, D. Okumura, and N. Ohno, "Yield and buckling behavior of Kelvin open-cell foams subjected to uniaxial compression," International Journal of Mechanical Sciences, vol. 52, no. 2, pp. 377-385, 2010.

[2] C. P. Gameiro and J. Cirne, "Dynamic axial crushing of short to long circular aluminium tubes with agglomerate cork filler," International Journal of Mechanical Sciences, vol. 49, no. 9, pp. 1029-1037, 2007.

[3] S. Banerjee and A. Bhaskar, "The applicability of the effective medium theory to the dynamics of cellular beams," International Journal of Mechanical Sciences, vol. 51, no. 8, pp. 598-608, 2009.

[4] M. F. Ashby, "The mechanical properties of cellular solids," Metallurgical and Materials Transactions A, vol. 14, no. 9, pp. 1755-1769, 1983.

[5] S. P. Silva, M. A. Sabino, E. M. Fernandas, V. M. Correlo, L. F. Boesel, and R. L. Reis, "Cork: properties, capabilities and applications," International Materials Reviews, vol. 50, no. 6, pp. 345-365, 2005.

[6] H. Pereira, M. E. Rosa, and M. A. Fortes, "The cellular structure of cork from Quercus suber L.," IAWA Bulletin, vol. 8, pp. 213218, 1987.

[7] M. Emilia Rosa and M. A. Fortes, "Stress relaxation and creep of cork," Journal of Materials Science, vol. 23, no. 1, pp. 35-42, 1988.

[8] J. F. Mano, "Creep-recovery behaviour of cork," Materials Letters, vol. 61, no. 11-12, pp. 2473-2477, 2007.

[9] N. Cordeiro, N. M. Belgacem, A. Gandini, and C. P. Neto, "Cork suberin as a new source of chemicals: 2. Crystallinity, thermal and rheological properties," Bioresource Technology, vol. 63, no. 2, pp. 153-158, 1998.

[10] C. V. Calahorro, A. B. Garcia, C. P. Barrera, M. J. B. Garcia, and M. G. Corzo, "Cation exchangers prepared from cork wastes," Bioresource Technology, vol. 44, no. 3, pp. 229-233, 1993.

[11] A. S. Mestre, J. Pires, J. M. F. Nogueira, J. B. Parra, A. P. Carvalho, and C. O. Ania, "Waste-derived activated carbons for removal of ibuprofen from solution: role of surface chemistry and pore structure," Bioresource Technology, vol. 100, no. 5, pp. 1720-1726, 2009.

[12] M. Wilsea, K. L. Johnson, and M. F. Ashby, "Indentation of foamed plastics," International Journal of Mechanical Sciences, vol. 17, no. 7, pp. 457-460, 1975.

[13] B. Lawn and R. Wilshaw, "Indentation fracture: principles and applications," Journal of Materials Science, vol. 10, no. 6, pp. 1049-1081, 1975.

[14] B. R. Lawn, N. P. Padture, H. Cai, and F. Guiberteau, "Making ceramics 'Ductile,' Science, vol. 263, no. 5150, pp. 1114-1116, 1994.

[15] Y. G. Jung, I. M. Peterson, A. Pajares, and B. R. Lawn, "Contact damage resistance and strength degradation of glass-infiltrated alumina and spinel ceramics," Journal of Dental Research, vol. 78, no. 3, pp. 804-814, 1999.

[16] M. A. Fortes and M. E. Rosa, "Densidade da cortiça: factores que a influenciam," Cortiça, vol. 593, pp. 65-69, 1988.

[17] J. V. Natividade, Subericultura, Direcçao Geral dos Serviços Florestais e Aquicolas, Lisbon, Portugal, 1990.

[18] F. Ben Abdallah, R. Ben Cheikh, M. Baklouti, Z. Denchev, and A. M. Cunha, "Characterization of composite materials based on PP-cork blends," Journal of Reinforced Plastics and Composites, vol. 25, no. 14, pp. 1499-1506, 2006.
[19] P. J. Antunes, G. R. Dias, A. T. Coelho, F. Rebelo, and T. Pereira, "Hyperelastic modelling of cork-polyurethane gel composites: non-linear FEA implementation in 3D foot model," Materials Science Forum, vol. 587-588, pp. 700-705, 2008.

[20] J. F. Mano, “The viscoelastic properties of cork," Journal of Materials Science, vol. 37, no. 2, pp. 257-263, 2002. 

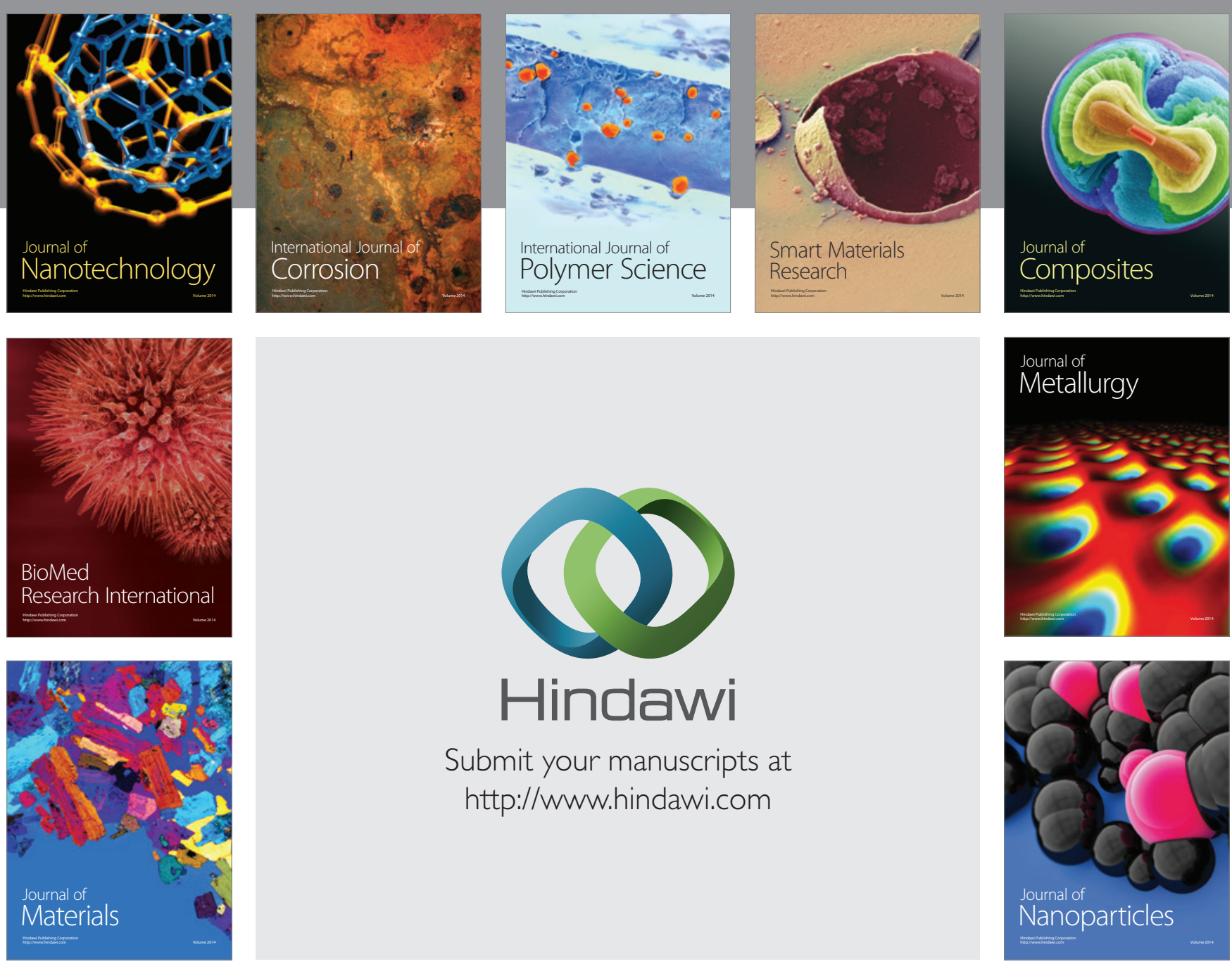

Submit your manuscripts at http://www.hindawi.com
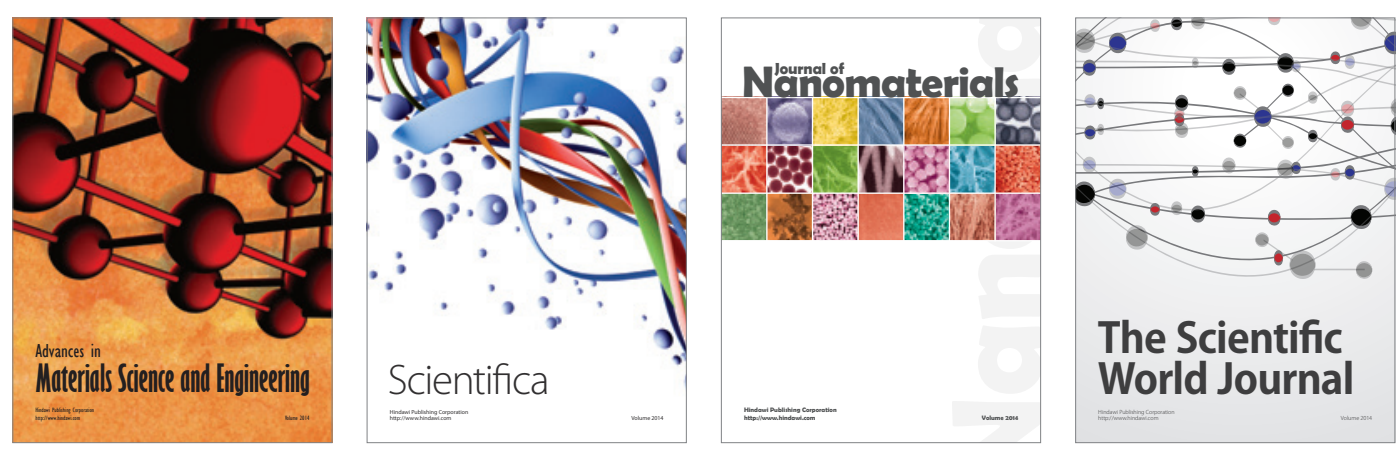

\section{The Scientific World Journal}
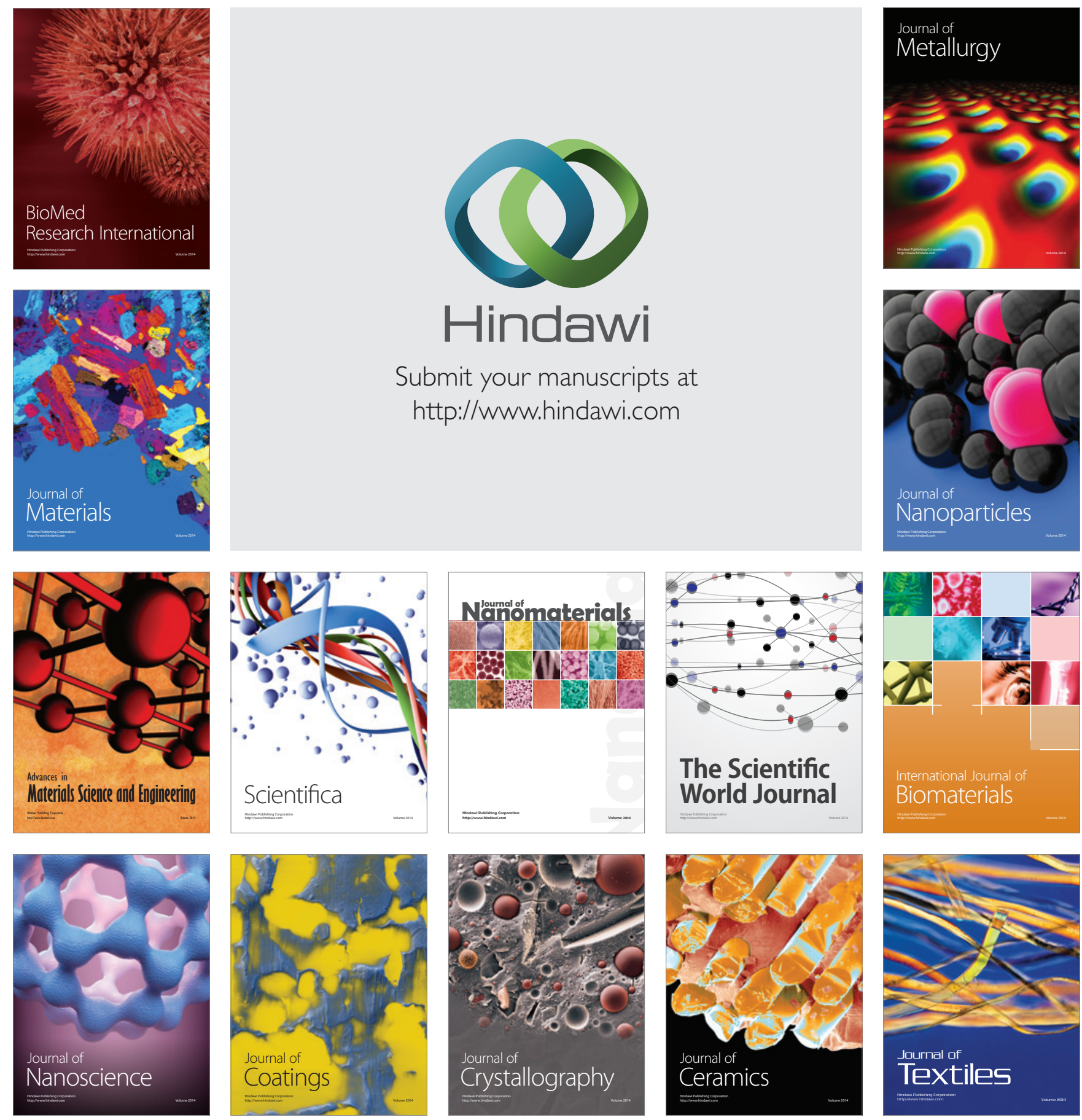